\title{
SP600125 enhances C-2-induced cell death by the switch from autophagy to apoptosis in bladder cancer cells
}

Haiyang $\mathrm{Yu}^{1 \dagger}$, Chun-Li Wu ${ }^{2 \dagger}$, Xiangyu Wang ${ }^{2}$, Qianhong Ban², Chunhua Quan², Mengbo Liu², Hangqi Dong ${ }^{2}$, Jinfeng $\mathrm{Li}^{3}$, Gi-Young Kim${ }^{4}$, Yung Hyun Choi ${ }^{5}$, Zhenya Wang ${ }^{2^{*}}$ and Cheng-Yun Jin ${ }^{2^{*}}$

\begin{abstract}
Background: A natural compound Jaspine B and its derivative possess potential anti-cancer activities; However, little is known about the underlying mechanism. Here, the role of a new autophagy inducer Jaspine B derivative C2 in suppressing bladder cancer cells was researched in vitro and in vivo.

Methods: The underlying mechanisms and anticancer effect of C-2 in bladder cancer cells were investigated by MTT, western blotting, immunoprecipitation and immunofluorescence assays. The key signaling components were investigated by using pharmacological inhibitors or specific siRNAs. In vivo, we designed a C-2 and SP600125 combination experiment to verify the effectiveness of compound.

Results: C-2 exhibits cytotoxic effect on bladder cancer cells, and JNK activated by C-2 triggers autophagy and upregulates SQSTM1/p62 proteins, contributing to activation of Nrf2 pathway. Utilization of JNK inhibitor SP600125 or knockdown of JNK by siRNA potentiate the cytotoxicity of C-2 through down-regulation of p62 and LC3II proteins and up-regulation of active-Caspase3 proteins, enhance the cell death effect, facilitating the switch from autophagy to apoptosis. In vivo study, C-2 suppresses tumor growth in a xenograft mouse model of EJ cells without observed toxicity. Combined treatment with SP600125 further enhances tumor inhibition of C-2 associated with enhanced activation of caspase 3 and reduction of autophagy.

Conclusions: It reveals a series of molecular mechanisms about SP600125 potentiate the cytotoxicity and tumor inhibition of $\mathrm{C}-2$ in bladder cancer cells through promoting C-2-induced apoptosis, expecting it provides research basis and theoretical support for new drugs development.
\end{abstract}

Keywords: SP600125, Autophagy, Apoptosis, Bladder cancer, C-2, SQSTM1/p62

\section{Background}

Bladder cancer is a common urologic cancer and is associated with substantial morbidity, mortality and cost [1]. Jaspine B, a novel anhydrophytosphingosine, was first isolated from a marine sponge Pachastrissa sp. in 2002 [2] (Fig. 1a), which exhibited a potent cytotoxicity at an $\mathrm{IC}_{50}$ level of $0.01 \mu \mathrm{g} / \mathrm{mL}$ against several tumor cell lines.

\footnotetext{
*Correspondence: barton118@163.com; cyjin@zzu.edu.cn

${ }^{+}$Haiyang Yu and Chun-Li Wu contributed equally to this work.

${ }^{2}$ School of Pharmaceutical Sciences, Key Laboratory of State Ministry of Education, Key Laboratory of Henan province for Drug Quality Control and Evaluation, Collaborative Innovation Center of New Drug Research and Safety Evaluation, Zhengzhou University, 100 Kexue Avenue, Zhengzhou 450001, Henan, China

Full list of author information is available at the end of the article
}

Our previous study reported that a new series of Jaspine $B$ derivatives were designed and synthesized, among them, compound $7 f$ was discovered as an autophagy inducer is associated with the up-regulation of LC3 and Beclin-1, and showed the best overall cytotoxicity on PC-3 cells [3]. And in that article, another compound 7 g (Fig. 1a, Fig. 2) also has significant cytotoxicity and could induce cell autophagy, due to the efficiency of Jaspine B derivatives was investigated in bladder cancer cells rarely, and the specific autophagy effect of compound $7 \mathrm{f}$ in PC3 cells had not been investigated deeply. Therefore, compound $7 \mathrm{~g}$ was selected and given chemical name of $\mathrm{C}-2$ to further research autophagy

(C) The Author(s). 2019 Open Access This article is distributed under the terms of the Creative Commons Attribution 4.0 International License (http://creativecommons.org/licenses/by/4.0/), which permits unrestricted use, distribution, and reproduction in any medium, provided you give appropriate credit to the original author(s) and the source, provide a link to the Creative Commons license, and indicate if changes were made. The Creative Commons Public Domain Dedication waiver (http://creativecommons.org/publicdomain/zero/1.0/) applies to the data made available in this article, unless otherwise stated. 


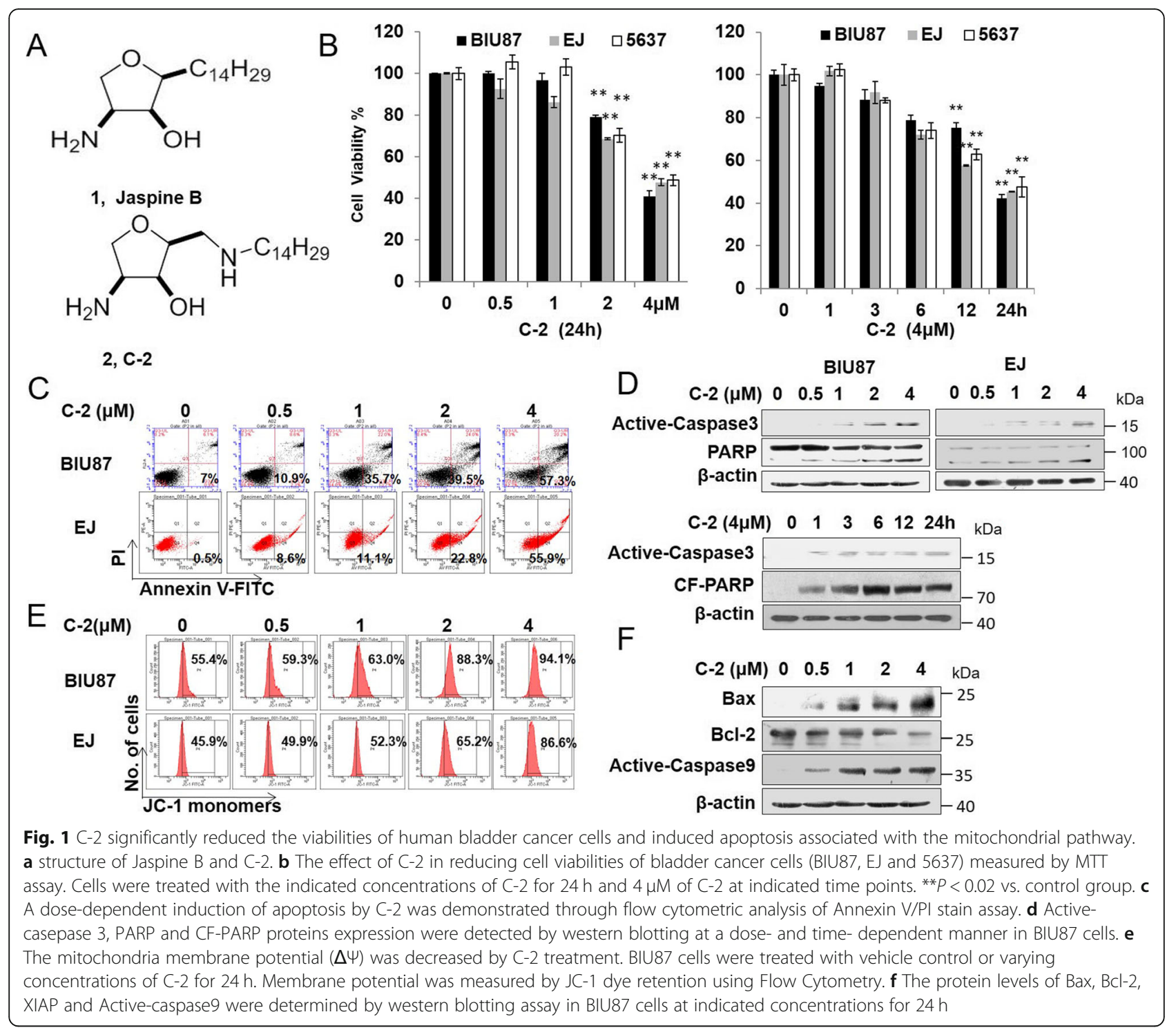

mechanism and its effect on bladder cancer cells and to evaluate its antitumor activities in this study.

Programmed cell death is categorized into two types: apoptosis (type I) and autophagy (type II). Autophagy is a cellular degradation mechanism while apoptosis is a self-killing mechanism [4]. Both processes can be triggered after cell injury and play an essential role in the development and tissue homeostasis of multicellular organisms, and the activation of apoptotic pathway are critical in suppressing the survival of different cancer cells [5]. Moreover, the anti-apoptotic proteins of the Bcl-2 family such as Bcl-2 and Bcl-xL could bind Beclin1 to inhibit autophagy. The effect of autophagy in cancer cells' response to chemotherapy is also complex: acting as a tumor suppressor and as a promoter of cell survival by increasing tumor growth [6].
JNK is a c-Jun N-terminal kinase and also known as a stress-responsive protein kinase of the MAPK family. JNK is primarily activated by various environmental stress include several antitumor proteins, stress signals and chemotherapy drugs, and JNK plays a critical role in the regulation of cell growth, differentiation, apoptosis and other signaling pathways [7]. Furthermore, growing evidence in recent years demonstrates JNK also contributes to autophagic induction through phosphorylating Bcl-2 and Bcl-xL to active Beclin-1 in response to various stress signals [8].

SQSTM1 (sequestosome 1)/p62 is an autophagy adaptor protein, binding ubiquitylated protein aggregates and delivering them to the autophagosomes. Recently, p62 has emerged as a multifaceted adaptor protein that exhibits diverse biological functions through the 


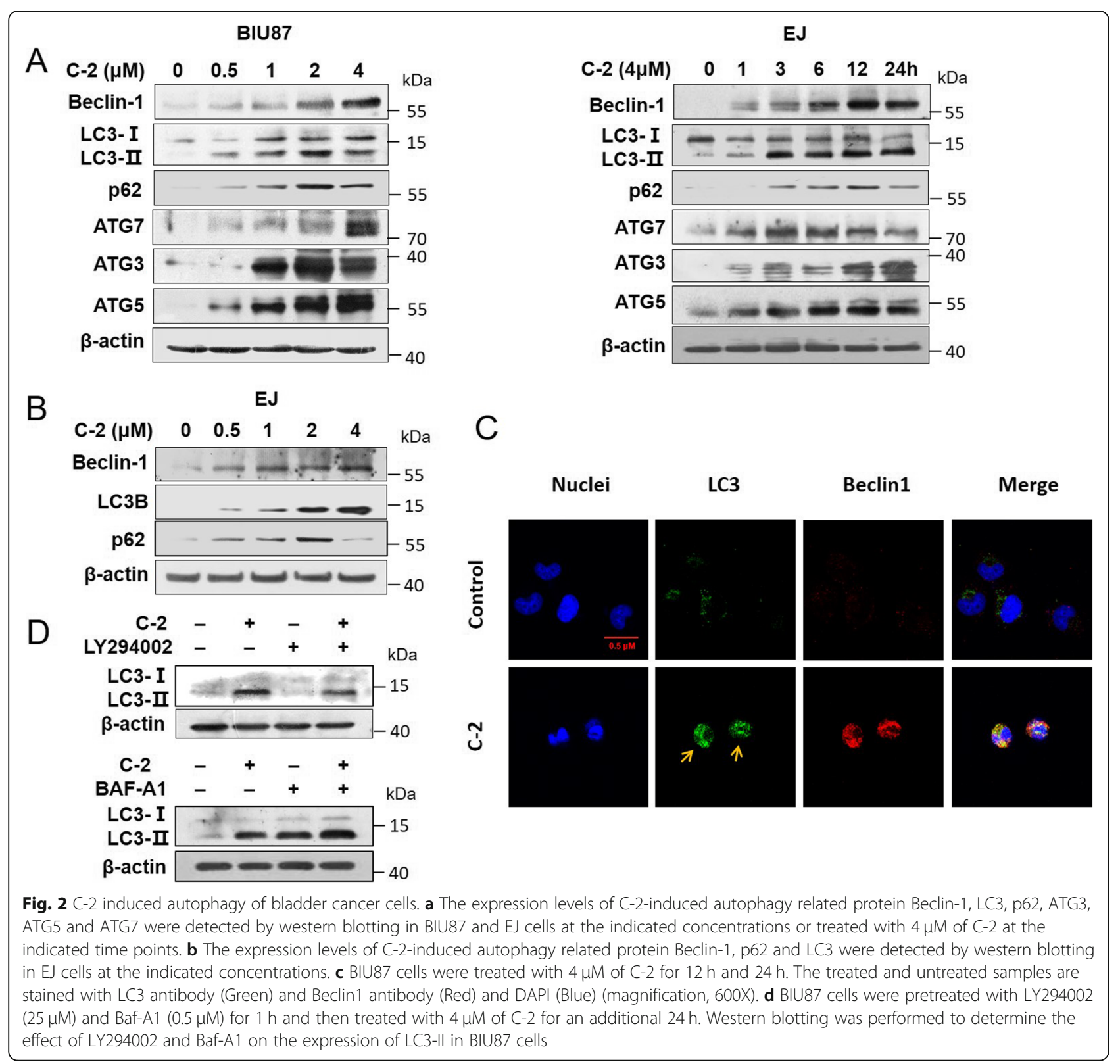

interaction with numerous proteins, and p62 is also identified as a new metabolic tumor suppressor [9]. The Kelch-like ECH-associated protein 1 (Keap1) and nuclear factor erythroid 2-related factor 2 (Nrf2) pathway is essential for cytoprotection against oxidative stress [10]. p62 could interacts with the Nrf2-binding site on Keap1, resulting in stabilization of Nrf2 and transcriptional activation of Nrf2 target genes, then perform cellular defense mechanisms against oxidative stresses [11]. Therefore, both the autophagy and Keap1-Nrf2 pathways are intimately linked by p62, antagonizing cellular stress by up-regulating a battery of antioxidant and cellular defense genes. The detailed mechanistic understanding of the interaction between the Keap1-Nrf2 and autophagy is a clear demonstration of the ongoing need for detailed mechanistic pictures of biological and pathological phenomena to facilitate the discovery of new therapies [12].

In many stress pathways, autophagy and apoptosis seem to co-exist simultaneously or interacted with the aid of mutual proteins, serving as a switching points critical to the ultimate outcome of the cells [13]. In particular situations, autophagy may antagonize apoptosis, and the cytoprotective function of autophagy in cancer cells has been suggested as a potential mechanism for chemoresistance [14]. However, when the intensity of the stress overcomes the protective barrier of autophagy, the cell becomes rapidly death. Therefore, the switch 
from autophagy to apoptosis suggested that autophagy induction was responsible for apoptotic lag phase and was an adaptive response [15]. The role of autophagy in cancer cells is controversial and it is urgent to research the effect of that on cancer.

Herein, in our study, C-2 exhibited cytotoxic effect against bladder cancer cells. We discussed the mechanism of C-2 on bladder cancer cells BIU87 and EJ with apoptosis and autophagy. Destruction of the crosstalk between p62 and Keap1-Nrf2 pathway through inhibiting the initiation of JNK-mediated autophagy by SP600125 triggering the switch from autophagy to apoptosis, which could be utilized for sensitizing bladder cancer cells to treatment with $\mathrm{C}-2$. We also evaluated antitumor activity of C-2 or combine with SP600125 in EJ tumor bearing xenograft mice model.

\section{Methods}

\section{Reagents}

Fetal bovine serum (FBS), RPMI-1640, and penicillinstreptomycin were purchased from HyClone (Victoria, Australia). 3-(4,5-dimethyl-thiazol-2-yl)-2, 5-diphenyltetrazolium bromide (MTT) and JC-1 fluorescent dye (SigmaAldrich, St Louis, MO), LY294002 and SP600125 (selleck, Texas, Houston), Protein A/G plus Agarose immunoprecipitation reagent (Santa Cruz, CA), DAPI (C0060, Solarbio, Beijing, China), lysis buffer (Beyotime, Shanghai, China), Annexin- V/FITC Apoptosis Detection Kit (BestBio, Shanghai, China). Antibodies specific for $\beta$-actin (sc-1615), Bax (sc-493), Bcl-2 (sc-783), Nrf2 (sc-13,032), c-Jun (sc-74,543) and p-c-Jun $(\mathrm{sc}-53,182)$ were obtained from Santa Cruz Biotechnology (Santa Cruz, CA). p-Nrf2 (ab76026), p62 (ab56416), Anti-active caspase 3 (ab2302) and anti-active caspase 9 (ab2324) were purchased from Abcam (Cambridge, MA). SAPK/JNK siRNA (\#6232), p62 siRNA (\#6394), Poly (ADP-ribose) polymerase-1 (PARP-1) (\#9532), Cleaved PARP (\#5625), NQO1 (\#3187), Keap1 (\#4617), Bcl-xL (\#2764), XIAP (\#14334), JNK (\#9252), pJNK (\#9255), LC3B (\#3868S) and Autophagy antibody sampler kit (\#4445) including Beclin-1, ATG16, ATG3, ATG7 and ATG5 were purchased from Cell Signaling Technology (Danvers, MA). The enhanced chemiluminescence (ECL) kit was purchased from ThermoFisher (Waltham, MA).

\section{Cell culture and proliferation}

BIU87, 5637 and EJ (human Bladder cancer cell) were obtained from ATCC. The used cells were resuscitated within 1 month, and cells preserved in liquid nitrogen and were expanded at low passages. Cells were in the logarithmic phase of growth for all experiments. Cells were cultured at $37^{\circ} \mathrm{C}$ in an atmosphere containing $5 \%$ $\mathrm{CO}_{2}$ with RPMI 1640 medium supplemented and $10 \%$ heat-inactivated fetal bovine serum, $100 \mathrm{U} / \mathrm{ml}$ penicillin and $0.1 \mathrm{mg} / \mathrm{ml}$ streptomycin. Cells were seeded into a 96-well plate at a density of 3,000 (100 $\mu \mathrm{l})$ cells per well for $24 \mathrm{~h}$ and followed by compound added $(200 \mu \mathrm{l})$ to the respective well in the indicated concentrations. Next, $20 \mu \mathrm{l}$ of $5 \mathrm{mg} / \mathrm{ml}$ MTT per well was added to the medium, and the cells were incubated for $4 \mathrm{~h}$ at $37^{\circ} \mathrm{C}$ and $5 \% \mathrm{CO}_{2}$. After removing the culture medium, $150 \mu \mathrm{l}$ of DMSO was added to dissolve the formazan crystal. The absorbance was read by enzyme labeling instrument with $490 \mathrm{~nm}$ wavelength measurement. The viability of the untreated cells was set as $100 \%$, and the viability of the other groups was calculated by comparing the optical density reading with the control. The $\mathrm{IC}_{50}$ value was calculated using nonlinear regression analysis.

\section{Apoptosis analysis}

BIU87 and EJ Cells were seeded at $1 \times 10^{5}$ cells per well in a 6-well plate and cultured for $24 \mathrm{~h}$. Next, the cells were exposed to different concentration of C-2 for $24 \mathrm{~h}$. After that, the cells were collected and washed with PBS twice, incubated with fluorescein isothiocyanate (FITC)conjugated Annexin V and PI by following FITC Annexin V/PI apoptosis kit instruction. Apoptotic cells were detected by flow cytometer. Annexin V+/PI- staining cells were counted as early apoptosis while Annexin $\mathrm{V}+\mathrm{PI}+$ positive staining cells as late apoptotic/necrotic cells.

\section{Measurement of loss of mitochondrial membrane potential (MMP, $\Delta \Psi$ )}

Cells were seeded at $1 \times 10^{5}$ per well in $10 \%$ FBS RPMI1640 into a 6-well plate, and treated with indicated concentration of C-2 for $24 \mathrm{~h}$. Then JC- $1(2.5 \mu \mathrm{g} / \mathrm{ml})$ probe for measurement of MMP, were added and incubated with an equal volume of cell suspension at $37^{\circ} \mathrm{C}$ for 10 $\mathrm{min}$ and rinsed twice with PBS. The concentration of retained JC-1 dye was determined by a flow cytometer (BD Biosciences).

\section{Western blot}

Cells $\left(6 \times 10^{5}\right)$ were cultured in each $100-\mathrm{mm}$ plate and treated with the indicated concentration of C-2 for $24 \mathrm{~h}$. Cells then were collected and lysed with ice-cold lysis buffer (Beyotime, Shanghai, China). After centrifugation at $12,000 \mathrm{rpm} / \mathrm{min}$ for $30 \mathrm{~min}$, protein concentrations of the lysates were determined by the micro-BCA protein assay kit. The total cellular protein extracts were boiled with $5 \times$ loading buffer, separated by SDS-PAGE and transferred to nitrocellulose membrane. After blocking with 5\% skimmed milk in PBST for $2 \mathrm{~h}$, the membranes were incubated with appropriate antibodies overnight at $4{ }^{\circ} \mathrm{C}$, followed by HRP conjugated anti-mouse, anti-goat or anti-rabbit secondary antibodies. The detection of specific proteins was carried out with an ECL Western blotting kit according to the recommended procedure. 


\section{Immunoprecipitation}

Cells were cultured in $100-\mathrm{mm}$ dishes, treated as indicated in figure legends, after treatments, cells were collected and lysed with ice-cold lysis buffer (Beyotime, Shanghai, China). Briefly, $500 \mu \mathrm{g}$ cell lysates were coupled to $1 \mu \mathrm{g}$ Beclin-1 antibody in lysis buffer for 30 min at $4{ }^{\circ} \mathrm{C}$. Then, $20 \mu \mathrm{l}$ of protein $\mathrm{A} / \mathrm{G}$ Agarose beads (50\%) were added by rotating overnight at $4{ }^{\circ} \mathrm{C}$. The beads were washed five times with PBS, then the samples were boiled for $5 \mathrm{~min}$ with $40 \mu \mathrm{l}$ of $1 \times$ loading buffer, and separated by $12 \%$ SDS-PAGE gel. The protein levels of Bcl-xL, Bcl-2 and Beclin-1 were measured by Western blot analysis.

\section{Immunofluorescence analysis of LC3 and Nrf2}

BIU87 cells were treated with $4 \mu \mathrm{M}$ of C-2 for $12 \mathrm{~h}$. Cells were fixed with $4 \%$ paraformaldehyde in PBS for $30 \mathrm{~min}$, permeabilized with $0.1 \%$ Triton X-100, and blocked with $10 \%$ normal goat serum for $30 \mathrm{~min}$. Incubation with primary antibodies against LC3 and Nrf2 was done overnight at $4{ }^{\circ} \mathrm{C}$. After washing, cells were exposed to FITCconjugated antibody (goat-anti-rabbit Ig $(\mathrm{H}+\mathrm{L})$-FITC). After washing, the nuclei were visualized with $2 \mu \mathrm{g} / \mathrm{ml}$ DAPI solution (dissolved with PBS) and added $10 \mathrm{~min}$ before imaging. The confocal microscopy (A1R+, Nikon, Tokyo, Japan) was used for co-localization analysis.

\section{Knockdown of JNK and p62 by siRNA}

The complex of Short-interfering RNAs for JNK and p62 with lipofectamine 2000 were prepared, BIU-87 cells were seeded in a 6-well plate the day before transfection at $30 \%$ confluency. $36 \mathrm{~h}$ after transfection, $4 \mu \mathrm{M}$ of $\mathrm{C}-2$ was added to the culture for $12 \mathrm{~h}$ and MTT analysis was determined to examine C-2-induced cytotoxicity, and knockdown confirmed by Western blot.

\section{Immunohistochemistry (IHC)}

Paraffin-embedded tissue sections were dewaxed and rehydrated, washed by PBS, following the antigen retrieval, endogenous peroxidase were blocked by $3 \%$ $\mathrm{H}_{2} \mathrm{O}_{2}$ for $20 \mathrm{~min}$, and normal goat serum was used to block non-specific binding sites for $20 \mathrm{~min}$, the sections were then incubated with active-caspase3, p62 and LC3 antibody diluted $1: 50$ in PBS at $4{ }^{\circ} \mathrm{C}$ overnight. Peroxidase-conjugated anti-rabbit antibodies were used for secondary detection, the reaction was revealed with diaminobenzidine (DAB). Sections were counterstained with hematoxylin.

\section{Tumor xenograft growth assay in vivo}

Animals were treated according to protocols established by the ethics committee of Zhengzhou University and the experiments in vivo were conducted according to the approved guidelines and approved by the ethics committee of Zhengzhou University. Forty male nude mice ( 5 weeks-old) were purchased from the Chinese Academy of Sciences (Beijing, China). Cells were digested and resuspended with PBS at a density of $1 \times$ 107 cells $/ \mathrm{ml}$. Cell suspension $(200 \mu \mathrm{l})$ was subcutaneously injected into the nude mice on the backside. Once tumors volume reached about $100 \mathrm{~mm}^{3}$ in size, mice were randomly divided into 4 groups ( $n=5$ per group). Group I received saline vehicle only and served as control. Group II received $10 \mathrm{mg} / \mathrm{kg} \mathrm{C}-2$ by intraperitoneal injection (i.p) every day. Group III received $5 \mathrm{mg} / \mathrm{kg}$ SP600125 (i.p) every day whereas Group IV received 10 $\mathrm{mg} / \mathrm{kg} \mathrm{C}-2$ as well as $5 \mathrm{mg} / \mathrm{kg} \mathrm{SP600125} \mathrm{(C-2/SP600125)}$ every day till day 21 . Mice were sacrificed at day 21 due to tumor burden. Tumor growth was monitored by tumor volume which was measured with calipers and calculated according to the formula, $\mathrm{V}=0.5 \times$ (length $\times$ width $\left.^{2}\right)$. Finally, tumors were harvested after 21 days (21 injections), body weight, tumor volume and tumor weight were measured.

\section{Statistical analysis}

The data are expressed as means \pm SD. Significant differences between the groups were determined using the unpaired Student's t-test. The statistically variation $P<$ 0.05 deemed as statistically significant.

\section{Results}

C-2 significantly reduced the viabilities of human bladder cancer cells and induced apoptosis associated with the mitochondrial pathway

To evaluate the effects of C-2 on human bladder cancer cells, three bladder cancer cell lines (BIU87, EJ and 5637) were incubated with $\mathrm{C}-2$ for indicated time points and concentrations, and then the effects of $\mathrm{C}-2$ on reducing cell viabilities were measured by an MTT assay. As shown in Fig. 1b, following treatment with $\mathrm{C}-2$, the viability of the bladder cancer cells decreased in a doseand time-dependent manner with $\mathrm{IC}_{50}$ values of 3.315 , 3.487, 3.724 $\mu \mathrm{M}$ respectively, and BIU87 and EJ cells showed the most sensitivity to $\mathrm{C}-2$ treatment. Taken together, these results suggested that C-2 has cytotoxicity against bladder cancer cells.

Further experiments were conducted to determine whether the inhibition of $\mathrm{C}-2$ on the viability of bladder cancer cells was the result of apoptotic cell death. Flow cytometry analysis and western blot results showed that C-2 dramatically increased the early and late apoptotic cells as well as the expression levels of Active-Casepase3 and CF-PARP proteins in BIU87 and EJ cells after $24 \mathrm{~h}$ treatment compare with the control group (Fig. 1c, d and Additional file 1: Figure S1A, B). Next, in order to confirm the involvement of mitochondrion in the induction of apoptosis caused by $\mathrm{C}-2$, the mitochondrial 
fluorescent probe JC-1 was used to measure mitochondrial membrane potential. After treatment with C-2, a right shift peak can be observed obviously compare with control (Fig. 1e), indicating that mitochondrial depolarization was induced by $\mathrm{C}-2$ in BIU87 and EJ cells. Western blot results showed that increasing levels of Bax and Active-caspase9 as well as decreasing expression levels of $\mathrm{Bcl}-2$ proteins in dose-dependent manner in BIU87 cells (Fig. If and Additional file 1: Figure S1C). These results together indicated that the mitochondrial pathway involved in C-2 induced apoptosis in bladder cancer cells.

\section{C-2 induced autophagy of bladder cancer cells}

As previously reported, the synthetic $\mathrm{C}-2$ homologous series of Jaspine $\mathrm{B}$ derivatives compound $7 \mathrm{f}$ resulted in autophagy in PC3 cells [3], therefore, we examined whether $\mathrm{C}-2$ could trigger autophagy in bladder cancer cells in this study. BIU87 cells were treated with C-2 in dose- or time-dependent manners, results showed that the expression level of LC3-II, Beclin-1, p62, Atg7, Atg3 and Atg5 proteins increased (Fig. 2a). Similarly, the expression level of LC3-II, p62 and Beclin-1 proteins also increased in EJ cells treated with $\mathrm{C}-2$ in dose-dependent manners (Fig. 2b). Immunoflorescence assay showed that punctate LC3 and Beclin1 as represented by green and red staining in BIU87 cells significantly enhanced after treated with $4 \mu \mathrm{M}$ of $\mathrm{C}-2$ for $12 \mathrm{~h}$ and $24 \mathrm{~h}$ (Fig. 2c). In addition, we evaluated the status of autophagic flux with an early stage autophagy inhibitor LY294002 that inhibits formation of autophagosomes and a late stage autophagy inhibitor Baf-A1 that blocks fusion with lysosomes [16]. LY294002 reduced the expression of LC3-II in C-2 treated BIU87 cells, while Baf-A1 caused an additive expression of LC3-II (Fig. 2d). Overall, C-2 induced the autophagy flux.

\section{C-2-induced autophagy is associated with JNK pathway by alleviating the suppression of $\mathrm{Bcl}-2$ and $\mathrm{Bcl}-\mathrm{xL}$ on Beclin-1 in bladder cancer cells}

To determine the signaling pathway that involved in C2-induced autophagy, the effect of C-2 on JNK pathway was investigated. Results showed both JNK and c-Jun proteins been phosphorylated and activated, which was related to the up-regulation of $\mathrm{p}$-JNK and $\mathrm{p}$-c-Jun in C2-treated BIU87 and EJ cells (Fig. 3a and Additional file 1: Figure S2). Moreover, whether C-2 led to dissociation of the Bcl-2/Beclin-1 and Bcl-xL/Beclin-1 complex through JNK pathway also was examined. Immunoprecipitation results revealed that Beclin-1 bound to $\mathrm{Bcl}-2$ and $\mathrm{Bcl}-\mathrm{xL}$ proteins in untreated cells, which was dissociated after $\mathrm{C}-2$ treatment causing a decrease of $\mathrm{Bcl}-2 / \mathrm{Bcl}-\mathrm{xL}$ expression. Interestingly, blocking JNK with pharmacological inhibitors SP600125 reversed the dissociation of the Bcl-2/Beclin-1 and Bcl-xL/Beclin-1 complex (Fig. $3 \mathrm{~b}$ ) and attenuated the expression level of LC3-II and Beclin1 proteins (Fig. 3c) caused by C-2 treatment, indicating that JNK pathway is a critical regulator of C-2-induced autophagy.

\section{Resisting C-2-induced apoptosis by p62 activated Nrf2 pathway in early time}

Since the p62 protein plays a significant role on autophagy process, the effect of p62 was investigated in our study. As shown in Fig. 4a, the expression levels of p62, p-Nrf2 and NQO1 was upregulated and reached its peak level at $12 \mathrm{~h}$ in $\mathrm{C}$-2-treated bladder cancer cells, and the expression of Nrf2 and Keap1 has no obviously changes. In addition, we evaluated the effects of $\mathrm{C}-2$ on target genes of Nrf2 such as NQO1, TrxR and IDH1, we found that C-2 clearly increases NQO1, TrxR and IDH1 mRNA levels (Additional file 1: Figure S3). Immunofluorescence assay showed accumulation of $\mathrm{Nrf} 2$ and p62 was higher within the nuclear following C-2 treatment (Fig. 4b). Immunoprecipitation noted that p62 bound with Keap1 at $6 \mathrm{~h}$ and then dramatically decreased (Fig. 4c), and utilization of p62 small interfering RNA (siRNA) decreased up-regulation of p-Nrf2 and the viability of BIU 87 cells treated by $\mathrm{C}-2$ (Fig. $4 \mathrm{~d}$ and e), indicating that $\mathrm{C}-2$ activated Nrf2 pathway through p62 to resisting apoptosis in early time.

\section{SP600125 block JNK-SQSTM1/p62-mediated Nrf2 anti- apoptotic pathway}

JNK inhibitor SP600125 was utilized to explore the potential effects of JNK on the p62-Keap1-Nrf2 pathway. As Fig. 5a, b and Additional file 1: Figure S4A showed that the binding of p62 and Keap1 proteins and the upregulation of p62, p-Nrf2 and NQO1 caused by $\mathrm{C}-2$ was attenuated by SP600125, whereas it enhanced the expression of CF-PARP and Active-caspase 3 proteins, and the expression of Nrf2 has no obviously changes. MTT results showed SP600125 obviously increased the cell death of BIU87 and EJ caused by C-2 (Fig. 5c). In addition, JNK siRNA increased the cell death of BIU87 and decreased expression of p62 and p-Nrf2 caused by $\mathrm{C}-2$, and the expression of Nrf2 has no obviously changes (Fig. 4d, e and Additional file 1: Figure S4B). These results suggested that blocking JNK resisted p62Nrf2 anti-apoptotic pathway and lead to the switch from autophagy to apoptosis, and JNK is the key regulatory molecules of $\mathrm{C}-2$ in bladder cancer cells.

\section{SP600125 potentiated the anti-tumor effect of C-2 in the xenograft nude mice model of EJ cells}

To evaluate the efficacy of $\mathrm{C}-2$ treatment in vivo and to establish the mechanism of tumor growth inhibition in bladder cancer, EJ cells were implanted subcutaneously 

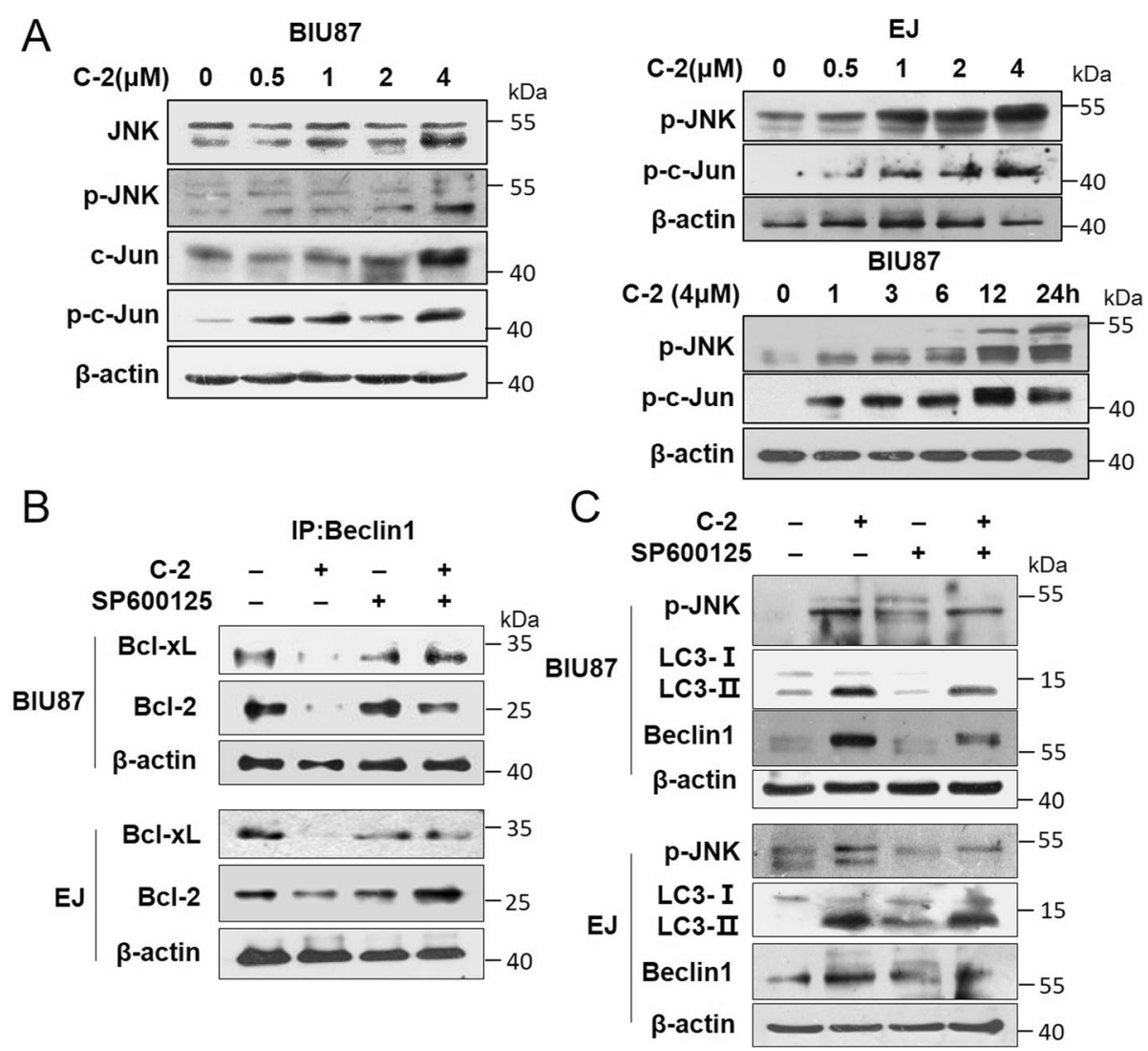

Fig. 3 C-2-induced autophagy is associated with JNK pathway by alleviating the suppression of BCl-2 and BCl-xL on Beclin-1 in bladder cancer cells. a. The phosphorylation of JNK and c-Jun were analyzed by western blotting at indicated concentration or treated with $4 \mu \mathrm{M}$ of $\mathrm{C}-2$ at indicated time points in BIU87 and EJ cells. b BIU87 and EJ cells were pretreated with $10 \mu \mathrm{M}$ of SP600125 for $1 \mathrm{~h}$ and then treated with $4 \mu \mathrm{M}$ of C-2 for an additional $24 \mathrm{~h}$. The indicated proteins were detected by western blotting after immunoprecipitation with an antibody for Beclin-1. c The effects of JNK inhibitor SP600125 (10 $\mu \mathrm{M})$ on $4 \mu \mathrm{M}$ of C-2-induced LC3-II and p-JNK expression changes of BIU87 and EJ cells

in nude mice. Since the establishment of the xenograft nude mouse tumor model with BIU87 cells is difficult, EJ bladder cancer cells were selected and study in vivo. SP600125 was utilized to further validate whether JNK pathway involved in C-2-induced autophagy in vivo, and the effect of JNK on tumor growth inhibition when SP600125 combined with C-2. Our results showed that C-2 treatment suppressed the growth of EJ tumors, and C-2/SP600125 group were significantly lower than those in mouse treated with vehicle or C-2 alone (Fig. 6a). There is no significant difference in mean body weights over time between vehicle control, C-2, SP600125 alone or $\mathrm{C}-2 / \mathrm{SP} 600125$ treated groups (Fig. 6b). The mean of wet tumor weights in $\mathrm{C}-2$ treated mice was less than that of the control treated mice, and C-2/SP600125 exhibited more obviously effect than that of $\mathrm{C}-2$ treated mice (Fig. 6c).

SP600125 was utilized to determine whether it potentiate the anti-tumor effect of $\mathrm{C}-2$ through blockage of JNK-mediated autophagy, tumors collected after humanely sacrificing the mice were subjected to immunohistochemical and western blot analysis. As shown in Fig. 6d and e, in agreement with our in vitro observations, our in vivo results demonstrated SP600125 increased expression of active-Caspase 3 and decreased the up-regulation of LC3 and p62 proteins induced by C-2 through western blot and immunohistochemistry analysis respectively in tumors. These results demonstrated SP600125 further enhanced the anti-tumor activity of $\mathrm{C}-2$ in the xenograft nude mice model of EJ cells through attenuating autophagy.

\section{Discussion}

Most patients with bladder cancer can be treated with organ-sparing therapy, radiotherapy and chemotherapy. Among these treatment schemes, chemotherapy is used as a primary or adjuvant therapy for treating cancer patients [1]. In recent years, naturally occurring botanicals and their derivatives are attracting considerable attention as cancer chemopreventive agents $[17,18]$. Jaspine B, a natural product derived from a marine sponge Pachastrissa $s p$., has exhibited potential antitumor activity in 


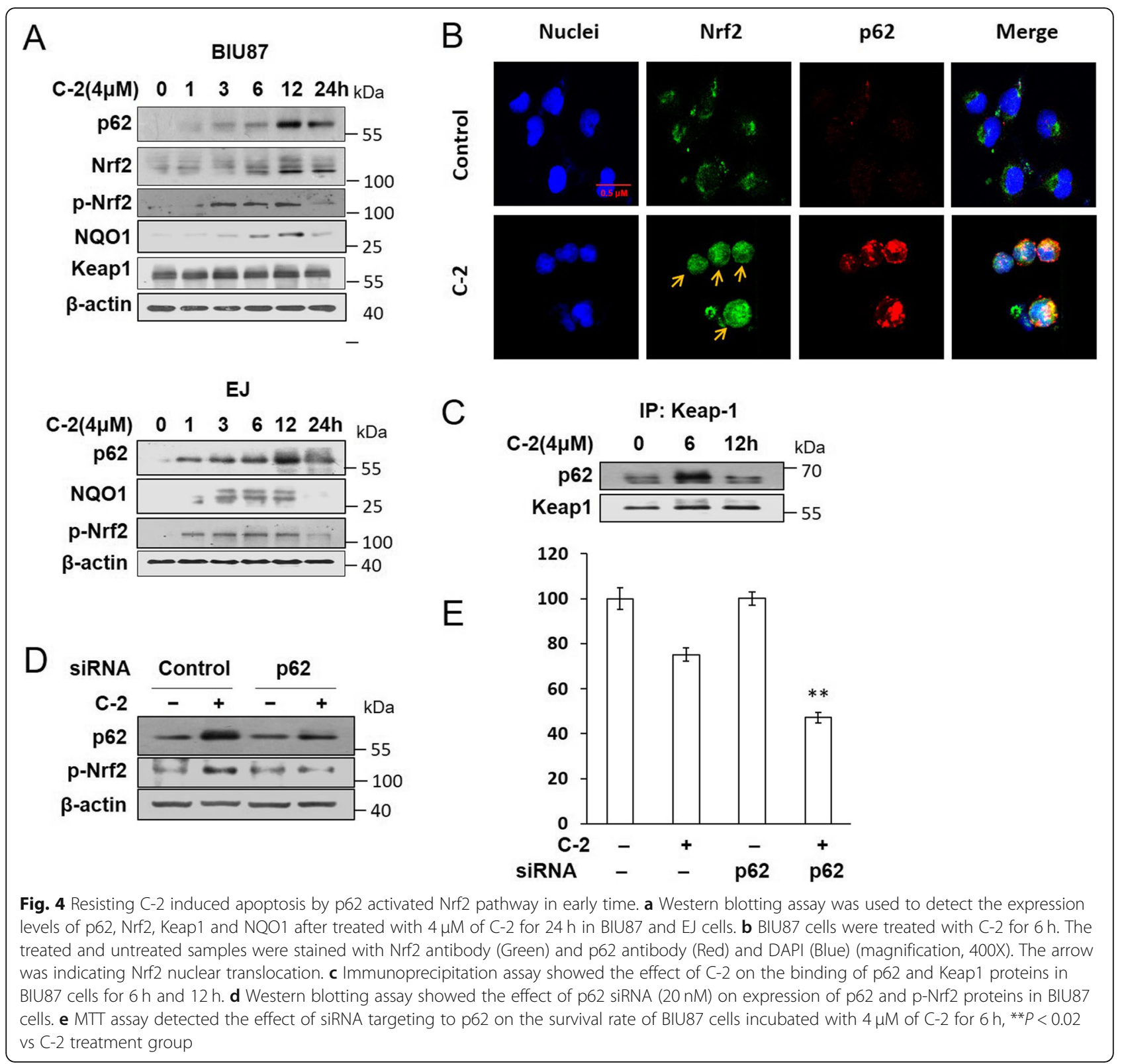

several tumor cell lines. However, detailed mechanism research of Jaspine B and its derivatives is still scarce, the role of autophagy in cell death and its cross-reaction with apoptosis are also still under investigation. Our previous study reported that Jaspine B derivatives compound $7 \mathrm{f}$ was discovered as an autophagy inducer and showed the best overall cytotoxicity on PC-3 cells [3]. In this study, another compound $7 \mathrm{~g}$ named $\mathrm{C}-2$ exhibited strong cytotoxic effect against bladder cancer cells, and the underlying mechanism of autophagy and apoptosis triggered by $\mathrm{C}-2$ and the crosstalk between autophagy and apoptosis were investigated in BIU87 and EJ cells.

It was reported that Jaspine B induced apoptosis in melanoma cells by interfering with ceramide metabolism [19].
In this study, the effect of apoptosis on bladder cancer cells induced by $\mathrm{C}-2$ was also identified. Results showed that $\mathrm{Bcl}-2$ family proteins alterations and mitochondrial membrane potential decreased by $\mathrm{C}-2$ treatment in bladder cancer cells, indicating that mitochondria pathway involved in C-2 induced apoptosis. More importantly, evidence demonstrated that damage and subsequent dysfunction of mitochondria can lead to a wide range of disorders due to the impact on cellular metabolism and the release of the apoptotic factors [20]. Consequently, autophagy degrades damaged mitochondria is critical for the overall health of the cell, suggesting that a mitochondrial balance is involved in regulating both types of cell death: autophagy and apoptosis [21]. 

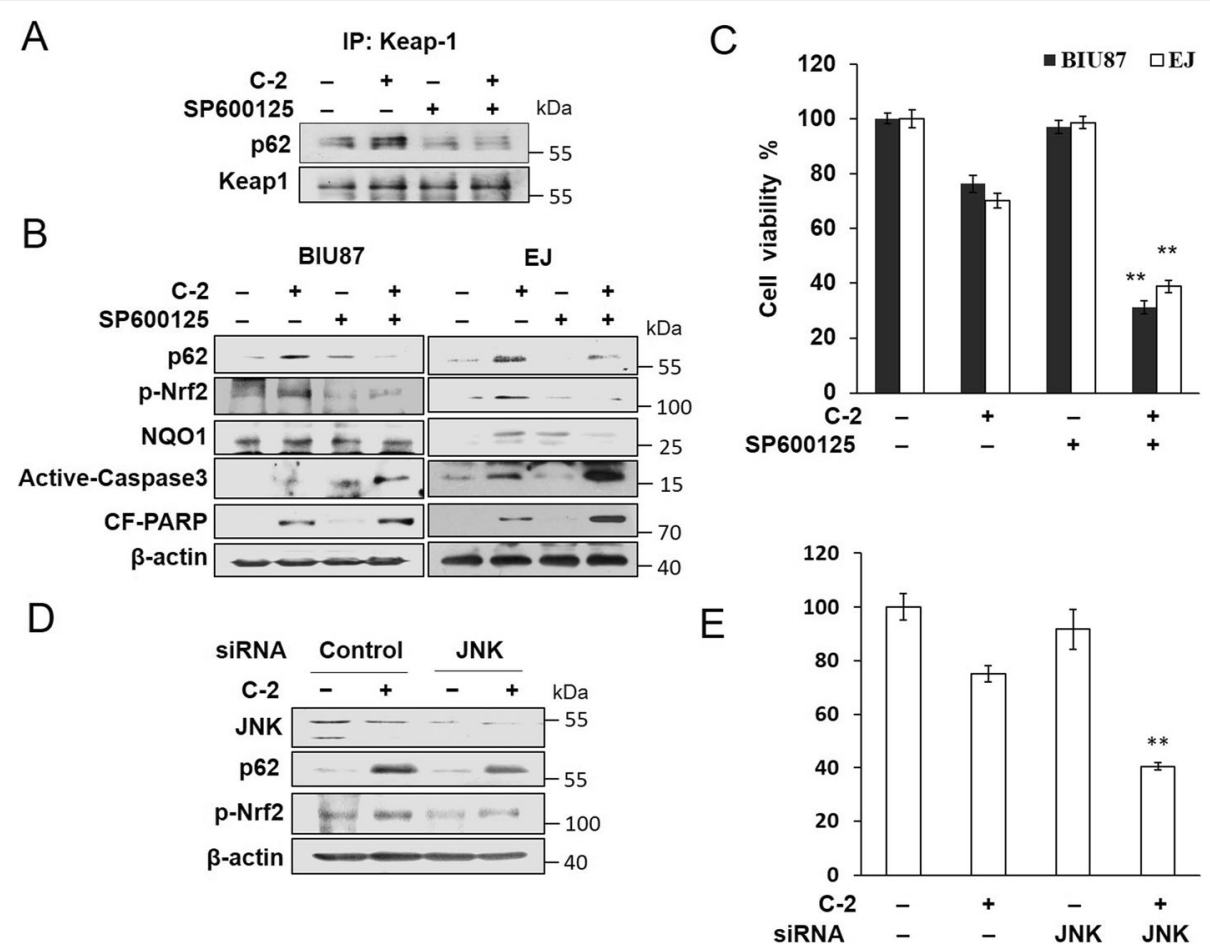

Fig. 5 SP600125 block JNK-SQSTM1/p62-mediated Nrf2 anti-apoptotic pathway. Immunoprecipitation (a) and Western blotting (b) assay showed the effect of SP600125 (10 $\mu \mathrm{M})$ on the expression changes of proteins in BIU87 cells incubated with $4 \mu \mathrm{M}$ of $\mathrm{C}-2$ for $6 \mathrm{~h}$. (c) MTT assay demonstrated the effect of SP600125 $(10 \mu \mathrm{M})$ on the cell viability of BIU87 and EJ treated by $4 \mu \mathrm{M}$ of C-2 for $6 \mathrm{~h}$. **P $<0.02$ vS C-2 treatment group. (d) Western blotting assay showed the effect of JNK siRNA $(20 \mathrm{nM})$ on expression of p62 and p-Nrf2 proteins in BIU87 cells. (e) MTT assay detected the effect of siRNA targeting to JNK on the survival rate of BIU87 cells incubated with $4 \mu \mathrm{M}$ of C-2 for $6 h,{ }^{* *} P<0.02$ vs C-2 treatment group

In addition to apoptosis, another process has a critical role in cancer therapy, which is autophagy. Myc is an oncogene that is often dysregulated in many cancers, and depletion of c-Myc impairs autophagy flux, thereby reducing phosphorylation of JNK and $\mathrm{Bcl}$ 2. Knockdown of this oncogene transcription factor disrupts the formation of autophagosomes [22-25]. Autophagy is an extremely complex process including many signaling pathways, such as the target of rapamycin, phosphatidylinositon3-kinae-I/protein kinase $\mathrm{B}$, guanosine triphosphate phosphohydrolase and MAPK pathways [26, 27]. Although it was reported that Jaspine B led to autophagy and anti-tumor activity in A549 cells [28], however, the mechanism of this action is not completely understood. In our study, the autophagy process induced by $\mathrm{C}-2$ is associated with autophagy factors such as ATG7, ATG5, ATG3, p62, LC3 and Beclin-1, therefore, the ability of $\mathrm{C}-2$ to induce autophagy in bladder cancer cell lines was confirmed. The autophagy flux covers autophagosome formation, maturation, fusion with lysosomes, subsequent breakdown and the release of macromolecules back into the cytosol. Here, Baf-A1 increased the accumulation of LC3-II proteins. In contrast, treatment with
LY294002 reduced LC3-II accumulation in BIU87 cells, demonstrating that $\mathrm{C}-2$ increased the autophagic flux [16]. And then went on to investigate the signaling pathways required for C-2-induced autophagy. Lin et al. [29] reported that cell autophagy through the AKT signaling pathway in T24 cells. Numerous published studies reported the activation of JNK had critical functions at upstream of autophagy induced by the deficiency of growth factors and nutrients, and stressing conditions [30, 31]. In this study, JNK activation triggered autophagy of bladder cancer cell through dissociation of the $\mathrm{Bcl}-2 / \mathrm{Bcl}-$ $\mathrm{xL}-$ Beclin-1 complex following C-2 treatment.

The p62, a selective substrate for autophagy, serves as a scaffold in autophagosomes through several structural domains, including the PB1 (Phox/Bem 1p), TB (TRAF6-binding), LIR (LC3-interacting region) and UBA (ubiquitin-associated) domains [32]. In this study, C-2 upregulated the expression of p62 and LC3-II at the protein levels. Similarly, tanshinone I, resveratrol and PMA increased autophagic flux with accumulation of intracellular p62 due to the enhancement of its synthesis as a compensation for autophagic degradation [33-35]. Thus, it can be assumed p62 induced by C-2 


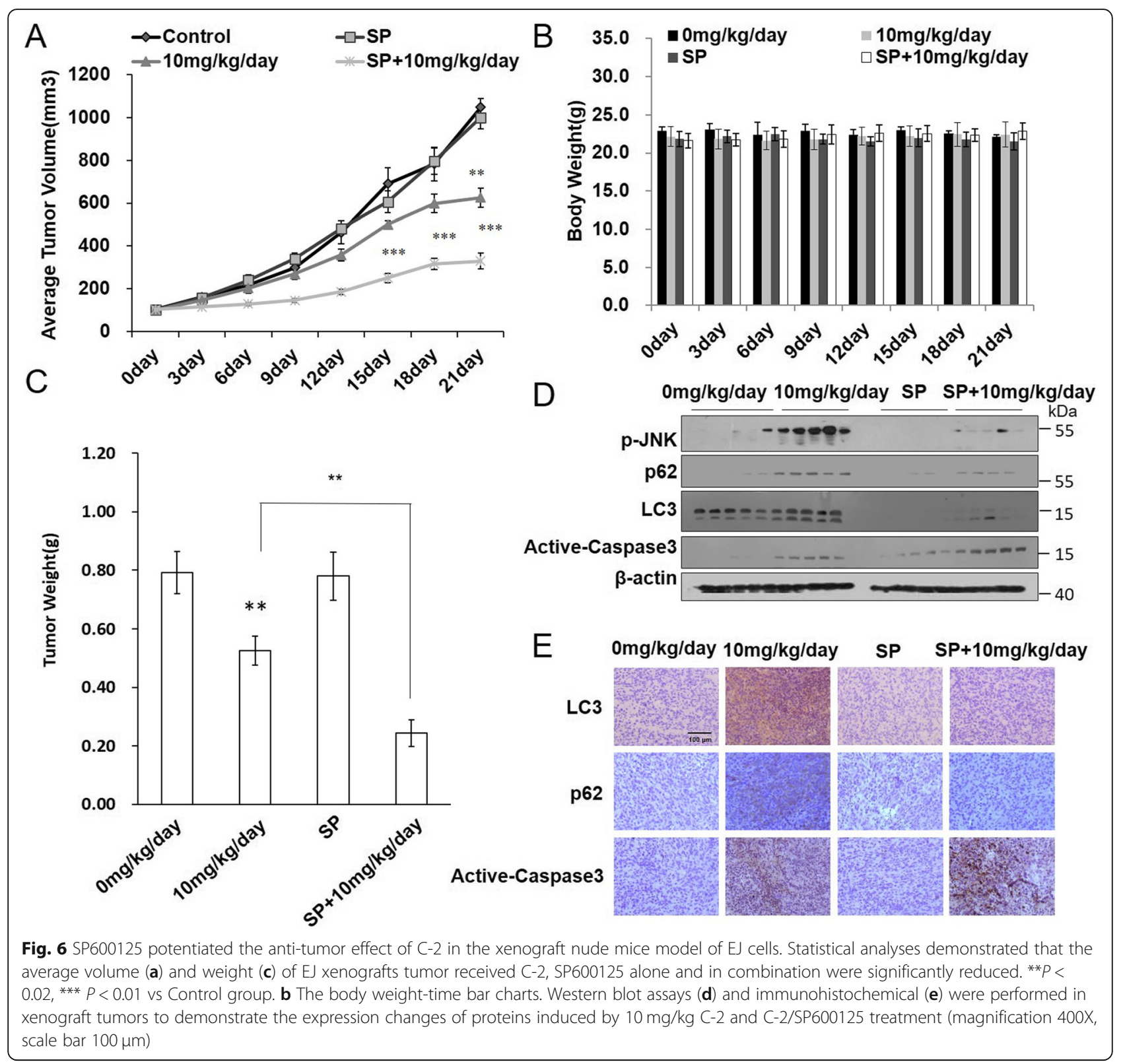

via its more synthesis compared with autophagic degradation.

Since p62 is also involved in various signal transduction pathways, such as the NF- $\mathrm{kB}$ pathway, Wnt signaling and apoptosis [36], furthermore, it is reported that p62 recruit RIPK1 to mediate necroptosis and lead to cell death occurs [37]. And p62 also contributed to Nrf2 signal pathway transduction to perform various functions. J. Shen et al. reported that p62-mediated Keap1/ Nrf2 signaling pathway could induce IFN $\alpha$ antiviral response inhibits HCV replication [38], whereas Sun X et al. reported that activation of the p62-Keap1-Nrf2 pathway protects against ferroptosis in hepatocellular carcinoma cells [39]. In this study, p62 interacted with the Nrf2-binding site on Keap1 was investigated through immunoprecipitation, resulting in activation of $\mathrm{Nrf} 2$ pathway and transcriptional activation of Nrf2 target genes NQO1, then perform cellular defense mechanisms to resisting apoptosis effect in the early stage after C-2 treatment.

Next, we went on to investigate the effect of JNK signaling pathways on p62-Nrf2 axis and apoptosis induced by $\mathrm{C}-2$, as well as the relation of them. Previous study reported that JNK pathways function could control the balance of autophagy and apoptosis in response to genotoxic stress [40]. Zhang et al. [41] reported 


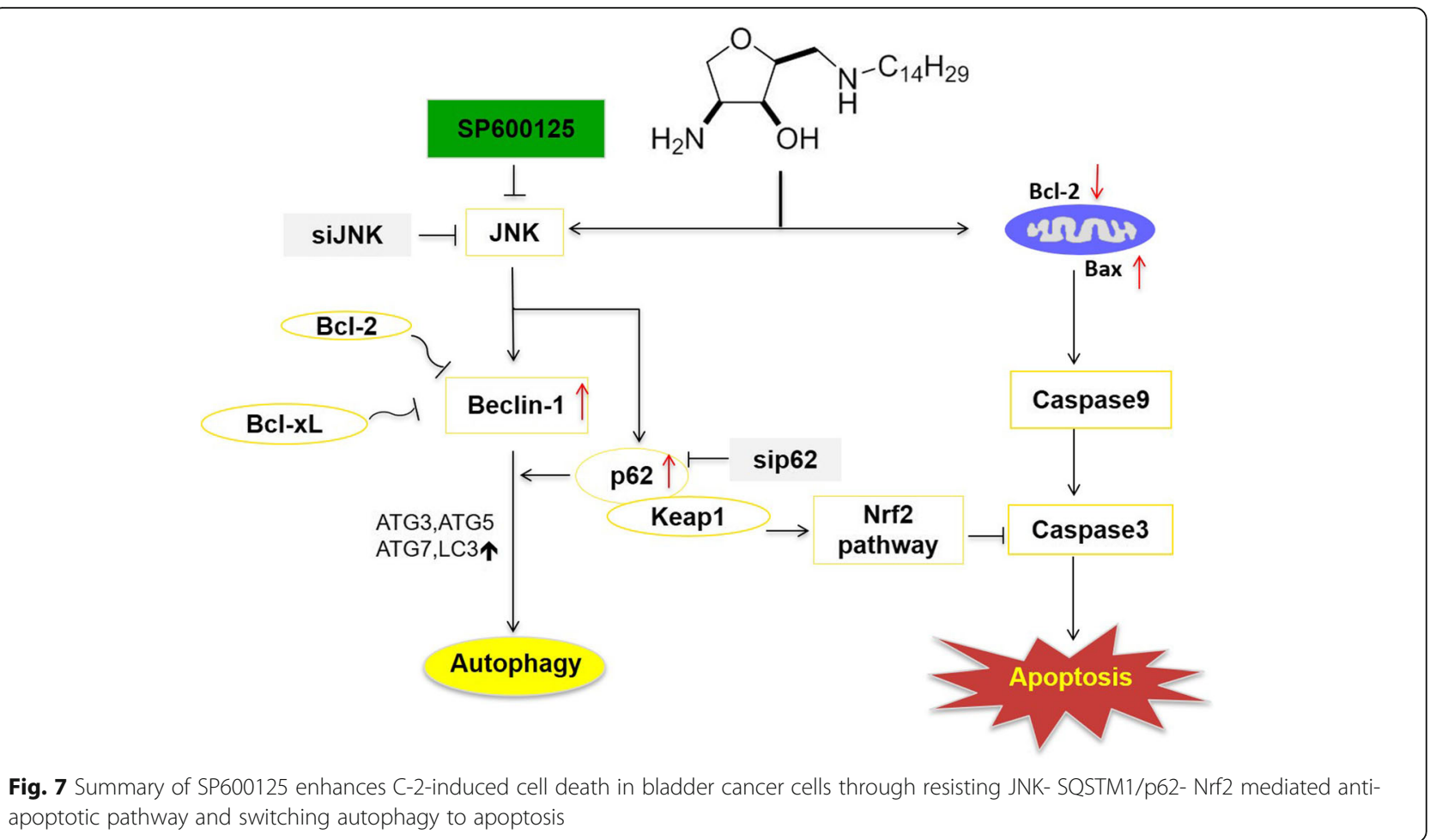

inhibiting JNK activation could decrease DNA damage levels in human HepG2 hepatoma cells. However, numerous published studies reported that blockage of JNK-mediated autophagy pathway increased the anticancer activity in several cancer cells $[42,43]$. In our study, SP600125 and utilization of JNK siRNA attenuated expression of p-Nrf2 and p62, promoted cytotoxicity and apoptosis triggered by $\mathrm{C}-2$ in bladder cancer cells, moreover, knockdown of p62 by siRNA drastically enhanced the cell death effect of $\mathrm{C}-2$. Taken together, blockage of JNK-p62-Nrf2 by SP600125 potentiates anti-cancer effect of $\mathrm{C}-2$ through triggering the switch from autophagy to apoptosis induced by $\mathrm{C}-2$.

In vivo study, we observed that $10 \mathrm{mg} / \mathrm{kg} \mathrm{C}-2$ significantly suppressed the growth of xenografts implanted EJ tumors. SP600125 combined with C-2 resulted in the increased efficacy of $\mathrm{C}-2$ in vivo and further suppressed the growth of EJ tumor. Western blot and immunohistochemistry demonstrated SP600125 further enhanced the anti-tumor effect of C-2 through switching autophagy to apoptosis, consistent with our in vitro observations. More importantly, our study expects to provide new direction for design drugs or combination therapy.

In many stress pathways such as nutrient depletion, hypoxia or chemotherapeutic treatment, autophagy and apoptosis seem to occur simultaneously in most cells [4]. Autophagy, in special case, is an immediate response and can be pro-survival under conditions of cellular stress such as environmental stimulate or chemotherapy. However, basal levels of autophagy maintain cellular homeostasis but under stress conditions that high levels of autophagy and cell death have been observed, leading to the idea that autophagy may act as an executioner of cell death [44]. In this study, the pro-death role of autophagy induced by $\mathrm{C}-2$ is however complicated due to the extensive crosstalk with apoptosis signaling pathways.

Overall, the mechanisms of the crosstalk between autophagy and apoptosis regulated by JNK-p62-Nrf2 axis in C-2-treated bladder cancer cells were confirmed (Fig. 7). To the best of our knowledge, C-2 as an autophagy inducer not only suppresses tumor growth but also the effect of that can be enhanced by SP600125. However, the effect of autophagy induced by $\mathrm{C}-2$ on the biological function of apoptotic nodes and signaling pathways on bladder cancer requires further research and it is significant to clarify the interrelationships between them.

\section{Conclusions}

Taken all together, these results suggest that C-2 maybe an attractive candidate for development of anti-tumor drugs targeting bladder cancer, and expecting it provides research basis and theoretical support for new drugs development. 


\section{Supplementary information}

Supplementary information accompanies this paper at https://doi.org/10. 1186/s13046-019-1467-6

Additional file 1: Figure S1. C-2 significantly induced apoptosis in human bladder cancer cells. (A) A dose-dependent induction of apoptosis by $\mathrm{C}-2$ was demonstrated through flow cytometric analysis of Annexin V/ PI stain assay. (B) The protein levels of Caspase9 were determined by western blotting assay at indicated concentrations for $24 \mathrm{~h}$. For A, data are shown as mean \pm s.d. $(n=3)$; ${ }^{*} P<0.01$; ${ }^{* *} P<0.001$ compared with control (Student's $t$ test). Figure S2. C-2-induced autophagy is associated with JNK pathway. The total of JNK and c-Jun were analyzed by western blotting at indicated concentration or treated with $4 \mu \mathrm{M}$ of $\mathrm{C}-2$ at indicated time points in BIU87 and EJ cells. Figure S3. Resisting C-2 induced apoptosis by p62 activated Nrf2 pathway in early time. The mRNA levels of NQO1, TrxR and IDH1 in BIU87 cells were detected by quantitative RTPCR. Data are shown as mean \pm s.d. $(n=3) ;{ }^{* *} P<0.001$ compared with control (Student's $t$ test). Figure S4. SP600125 block JNK-SQSTM1/p62mediated Nrf2 anti-apoptotic pathway. (A) Western blotting assay showed the effect of SP600125 (10 $\mu \mathrm{M})$ on the expression changes of $\mathrm{Nrf} 2$ protein in BIU87 cells incubated with $4 \mu \mathrm{M}$ of $\mathrm{C}-2$ for $6 \mathrm{~h}$. (B) Western blotting assay showed the effect of JNK siRNA (20 nM) on expression of Nrf2 protein in BIU87 cells.

\section{Abbreviations}

]PARP: Poly (ADP-ribose) polymerase; Atgs: Autophagy-related genes; BafA1: Bafilomycin A1; JNK: c-Jun N-terminal kinase; Keap1: The Kelch-like ECHassociated protein 1; LC3II: Microtubule-associated protein 1A/1B-light chain 3ll; MMP: Mitochondrial membrane potential; Nrf2: Nuclear factor erythroid 2related factor 2; p62: SQSTM1 (sequestosome 1)/p62

\section{Acknowledgements}

We would like to thank Dr. Yuling Qiu (Tianjin Medical University) for language editing.

\section{Authors' contributions}

CYJ, ZW, conceived and designed research; CYJ, HY, CLW and XW analyzed data and wrote the manuscript; $X W, H Y, Q B, M L$ performed the experiments; $C Q, H D$ performed animal experiment; JL, GYK, YHC contributed new reagents and analytic tools. All authors read and approved the final manuscript.

\section{Funding}

This work was supported by National Natural Science Foundation of China (No. 81973529 for Cheng-Yun Jin, No. 81873089 for Haiyang. Yu), The National Key R\&D Program (No.2017YFD0501401 for Chun-Li Wu), The Opening and Cooperation Program of Science and Technology of Henan Province (No. 172106000008 for Chun-Li Wu); The Scientific Innovation Talent Award from Department of Education of Henan Province (No. 15HASTIT036 for Cheng-Yun Jin); and Fang's family (Hong Kong) foundation (Zhenya Wang).

\section{Availability of data and materials}

Supplemental figure and associated figure legends are provided in supplemental material and are available online with the paper.

\section{Ethics approval and consent to participate}

Animals were treated according to protocols established by the ethics committee of Zhengzhou University and the experiments in vivo were conducted according to the approved guidelines and approved by the ethics committee of Zhengzhou University.

\section{Consent for publication}

All authors have seen the manuscript and approved to submit to your journal.

\section{Competing interests}

The authors declare that they have no competing interests.

\section{Author details}

${ }^{1}$ Tianjin State Key Laboratory of Modern Chinese Medicine, Tianjin University of Traditional Chinese Medicine, 312 Anshanxi Road, Nankai District, Tianjin 300193, China. ${ }^{2}$ School of Pharmaceutical Sciences, Key Laboratory of State Ministry of Education, Key Laboratory of Henan province for Drug Quality Control and Evaluation, Collaborative Innovation Center of New Drug Research and Safety Evaluation, Zhengzhou University, 100 Kexue Avenue, Zhengzhou 450001, Henan, China. ${ }^{3}$ Kidney Transplantation, The First Affiliated Hospital of Zhengzhou University, No. 1 Jianshe Road, Erqi District, Zhengzhou 450001, Henan, China. ${ }^{4}$ Department of Marine Life Sciences, Jeju National University, Jeju 63243, Republic of Korea. ${ }^{5}$ Department of Biochemistry, College of Oriental Medicine, Dong-Eui University, Busan 47227, Republic of Korea.

Received: 19 August 2019 Accepted: 23 October 2019

Published online: 04 November 2019

\section{References}

1. Sanli O, Sanli O, Dobruch J, Knowles MA, Burger M, Alemozaffar M, Nielsen ME, et al. Bladder cancer. Nat Rev Dis Primers. 2017:3:17022.

2. Kuroda I, Musman M, Ohtani II, Ichiba T, Tanaka J, Gravalos DG, et al. Pachastrissamine, a cytotoxic anhydrophytosphingosine from a marine sponge, Pachastrissa sp. J Nat Prod. 2002;65:1505-6.

3. Zhang E, Wang S, Li LL, Hua YG, Yue JF, Li JF, et al. Discovery of novel jaspine B analogues as autophagy inducer. Bioorg Med Chem Lett. 2017:28:497-502.

4. Marino G, Niso-Santano M, Baehrecke EH, Kroemer G. Self-consumption: the interplay of autophagy and apoptosis. Nat Rev Mol Cell Biol. 2014;15:81-94.

5. Uzzo RG, Haas NB, Crispen PL, Kolenko VM. Mechanisms of apoptosis resistance and treatment strategies to overcome them in hormonerefractory prostate cancer. Cancer. 2008;112:1660-71.

6. Singh R, Cuervo AM. Autophagy in the cellular energetic balance. Cell Metab. 2011:13:495-504.

7. Manning AM, Davis RJ. Targeting JNK for therapeutic benefit: from junk to gold? Nat Rev Drug Discov. 2003;2:554-65.

8. Yang J, Yao S. JNK-BCl-2/BCl-XL-Bax/Bak pathway mediates the crosstalk between Matrine-induced autophagy and apoptosis via interplay with Beclin 1. Int J Mol Sci. 2015;16:25744-58.

9. Leong I. p62 - a new metabolic tumour suppressor. Nat Rev Endocrinol. 2018;14:29692410.

10. Zhang S, Li T, Zhang L, Wang X, Dong H, Li L, et al. A novel chalcone derivative $\mathrm{S} 17$ induces apoptosis through ROS dependent DR5 upregulation in gastric cancer cells. Sci Rep. 2017;7:9873.

11. Komatsu M, Kurokawa H, Waguri S, Taguchi K, Kobayashi A, Ichimura $Y$, et al The selective autophagy substrate p62 activates the stress responsive transcription factor Nrf2 through inactivation of Keap1. Nat Cell Biol. 2010;12:213-23.

12. Jiang $T$, Harder B, de la vega Rojo M, Wong PK, Chapman E, Zhang DD. p62 links autophagy and Nrf2 signaling. Free Radic Biol Med. 2015;88:199-204.

13. Vijayarathna S, Gothai S, Jothy SL, Chen Y, Kanwar JR, Sasidharan S. Can Cancer therapy be achieved by bridging apoptosis and autophagy: a method based on microRNA-dependent gene therapy and phytochemical targets. Asian Pac J Cancer Prev. 2015;16:7435-9.

14. Gordy C, He YW. The crosstalk between autophagy and apoptosis: where does this lead? Protein Cell. 2012;3:17-27.

15. Antonioli M, Di Rienzo M, Piacentini M, Fimia GM. Emerging mechanisms in initiating and terminating autophagy. Trends Biochem Sci. 2017;42:28-41.

16. Klionsky DJ, Abdelmohsen K, Abe A, Abedin MJ, Abeliovich H, Acevedo Arozena $\mathrm{A}$, et al. Guidelines for the use and interpretation of assays for monitoring autophagy (3rd edition). Autophagy. 2016;12:1-222.

17. Mudit M, El Sayed KA. Cancer control potential of marine natural product scaffolds through inhibition of tumor cell migration and invasion. Drug Discov Today. 2016;21:1745-60.

18. Zhang S, Li T, Zhang Y, Xu H, Li Y, Zi X, et al. A new brominated chalcone derivative suppresses the growth of gastric cancer cells in vitro and in vivo involving ROS mediated up-regulation of DR5 and 4 expression and apoptosis. Toxicol Appl Pharmacol. 2016;309:77-86.

19. Salma Y, Lafont E, Therville N, Carpentier S, Bonnafe MJ, Levade T, et al. The natural marine anhydrophytosphingosine, Jaspine $B$, induces apoptosis in melanoma cells by interfering with ceramide metabolism. Biochem Pharmacol. 2009;78:477-85. 
20. Marquez-Jurado S, Diaz-Colunga J, das Neves RP, Martinez-Lorente A, Almazan F, Guantes R, et al. Mitochondrial levels determine variability in cell death by modulating apoptotic gene expression. Nat Commun. 2018;9:389.

21. Anding AL, Baehrecke EH. Cleaning house: selective autophagy of organelles. Dev Cell. 2017;41:10-22.

22. Yoshida GJ. Therapeutic strategies of drug repositioning targeting autophagy to induce cancer cell death: from pathophysiology to treatment. J Hematol Oncol. 2017;10:28279189.

23. Toh PP, Luo S, Menzies FM, Raskó T, Wanker EE, Rubinsztein DC. Myc inhibition impairs autophagosome formation. Hum Mol Genet. 2013;22:5237-48

24. Yoshida GJ. Emerging roles of Myc in stem cell biology and novel tumor therapies. J Exp Clin Cancer Res. 2018;37:30053872.

25. Granato M, Rizzello C, Romeo MA, Yadav S, Santarelli R, D'Orazi G, et al. Concomitant reduction of c-Myc expression and PI3K/AKT/mTOR signaling by quercetin induces a strong cytotoxic effect against Burkitt's lymphoma. Int J Biochem Cell Biol. 2016;79:393-400.

26. Dikic I, Elazar Z. Mechanism and medical implications of mammalian autophagy. Nat Rev Mol Cell Biol. 2018;19:29618831.

27. Green Douglas R, Levine B. To be or not to be? How selective autophagy and cell death govern cell fate. Cell. 2014;157:65-75.

28. Canals D, Mormeneo D, Fabrias G, Llebaria A, Casas J, Delgado A. Synthesis and biological properties of Pachastrissamine (jaspine B) and diastereoisomeric jaspines. Bioorg Med Chem. 2009;17:235-41.

29. Lin C, Tsai SC, Tseng MT, Peng SF, Kuo SC, Lin MW, et al. AKT serine/ threonine protein kinase modulates baicalin-triggered autophagy in human bladder cancer T24 cells. Int J Oncol. 2013:42:993-1000.

30. Hu F, Han J, Zhai B, Ming X, Zhuang L, Liu Y, et al. Blocking autophagy enhances the apoptosis effect of bufalin on human hepatocellular carcinoma cells through endoplasmic reticulum stress and JNK activation. Apoptosis. 2014;19:210-23.

31. Liu AJ, Wang SH, Chen KC, Kuei HP, Shih YL, Hou SY, et al. Evodiamine, a plant alkaloid, induces calcium/JNK-mediated autophagy and calcium/ mitochondria-mediated apoptosis in human glioblastoma cells. Chem Biol Interact. 2013;205:20-8.

32. Komatsu M. Potential role of p62 in tumor development. Autophagy. 2014 7:1088-90

33. Colosetti P, Puissant A, Robert G, Luciano F, Jacquel A, Gounon P, et al. Autophagy is an important event for megakaryocytic differentiation of the chronic myelogenous leukemia K562 cell line. Autophagy. 2009;5: 1092-8.

34. Lee J, Sohn EJ, Yoon S, Won G, Kim CG, Jung JH, et al. Activation of JNK and IRE1 is critically involved in tanshinone l-induced p62 dependent autophagy in malignant pleural mesothelioma cells: implication of p62 UBA domai. Oncotarget. 2017;8:25032-45.

35. Puissant A, Robert G, Fenouille N, Luciano F, Cassuto JP, Raynaud S, et al. Resveratrol promotes autophagic cell death in chronic myelogenous leukemia cells via JNK-mediated p62/SQSTM1 expression and AMPK activation. Cancer Res. 2010:70:1042-52.

36. Reina-Campos M, Shelton PM, Diaz-Meco MT, Moscat J. Metabolic reprogramming of the tumor microenvironment by p62 and its partners. Biochim Biophys Acta. 2018;1870:29702207.

37. Goodall ML, Fitzwalter BE, Zahedi S, Wu M, Rodriquez D, Mulcahy-Levy JM, et al. The autophagy machinery controls cell death switching between apoptosis and Necroptosis. Dev Cell. 2016:37:337-49.

38. Shen J, Wang G, Zuo J. Caffeic acid inhibits HCV replication via induction of IFNalpha antiviral response through p62-mediated Keap1/Nrf2 signaling pathway. Antivir Res. 2018;154:166-73.

39. Sun X, Ou Z, Chen R, Niu X, Chen D, Kang R, et al. Activation of the p62Keap1-NRF2 pathway protects against ferroptosis in hepatocellular carcinoma cells. Hepatology. 2016;63:173-84.

40. Sui X, Kong N, Ye L, Han W, Zhou J, Zhang Q, et al. p38 and JNK MAPK pathways control the balance of apoptosis and autophagy in response to chemotherapeutic agents. Cancer Lett. 2014;344:174-9.

41. Zhang Z, Ren Z, Chen S, Guo X, Liu F, Guo L, et al. ROS generation and JNK activation contribute to 4-methoxy-TEMPO-induced cytotoxicity, autophagy, and DNA damage in HepG2 cells. Arch Toxicol. 2018;92:717-28.

42. He W, Wang Q, Xu J, Xu X, Padilla MT, Ren G, et al. Attenuation of TNFSF10/TRAIL-induced apoptosis by an autophagic survival pathway involving TRAF2- and RIPK1/RIP1-mediated MAPK8/JNK activation. Autophagy. 2012;8:1811-21.
43. Kim MO, Lee HS, Chin YW, Moon DO, Ahn JS. Gartanin induces autophagy through JNK activation which extenuates caspase-dependent apoptosis. Oncol Rep. 2015;34:139-46.

44. Denton D, Xu T, Kumar S. Autophagy as a pro-death pathway. Immunol Cell Biol. 2015;93:35-42.

\section{Publisher's Note}

Springer Nature remains neutral with regard to jurisdictional claims in published maps and institutional affiliations.

\section{Ready to submit your research? Choose BMC and benefit from:}

- fast, convenient online submission

- thorough peer review by experienced researchers in your field

- rapid publication on acceptance

- support for research data, including large and complex data types

- gold Open Access which fosters wider collaboration and increased citations

- maximum visibility for your research: over $100 \mathrm{M}$ website views per year

At BMC, research is always in progress.

Learn more biomedcentral.com/submissions 